\title{
Erratum to: Combining forces: the promise and peril of synergistic immune checkpoint blockade and targeted therapy in metastatic melanoma
}

David J. Hermel ${ }^{1} \cdot$ Patrick A. Ott $^{2}$

Published online: 22 March 2017

(C) Springer Science+Business Media New York 2017

Erratum to: Cancer Metastasis Rev

DOI 10.1007/s10555-017-9656-2

The original version of this article unfortunately contained a mistake. The middle initial of Patrick A. Ott was not captured. The correct name is now presented above.

The online version of the original article can be found at http://dx.doi. org/10.1007/s10555-017-9656-2.

Patrick A. Ott

Patrick_Ott@DFCI.harvard.edu

1 Resident Physician, University of Southern California, Los Angeles, CA, USA

2 Melanoma Disease Center and Center for Immuno-Oncology, Dana-Farber Cancer Institute/Harvard Medical School,

Boston, MA 02215-5450, USA 